\title{
FUNCIONALIDADE DE HIDROLISADOS PROTEICOS DE CABRINHA (Prionotus punctatus) OBTIDOS A PARTIR DE DIFERENTES PROTEASES MICROBIANAS
}

\author{
Elessandra da Rosa Zavareze, Carolina Moroni Silva, Myriam Salas-Mellado e Carlos Prentice-Hernández* \\ Escola de Química e Alimentos, Universidade Federal do Rio Grande, CP 474, 96201-900 Rio Grande - RS, Brasil
}

Recebido em 3/7/08; aceito em 3/3/09; publicado na web em 10/8/09

\begin{abstract}
FUNCTIONALITY OF BLUEWING SEAROBIN (Prionotus punctatus) PROTEIN HYDROLYSATES OBTAINED FROM DIFFERENT MICROBIAL PROTEASES. The objective of this work was to study the influence of enzymes Alcalase, Flavourzyme and Novozym in the functional properties of hydrolysates of Bluewing searobin (Prionotus punctatus) minced. The hydrolysates of Bluewing searobin were evaluated for the chemical composition and the functional properties. The Novozym enzyme presented greater specific activity differing significantly from the enzymes Alcalase and Flavourzyme. The hydrolysates of Bluewing searobin presented protein content above of $87 \%$ and excellent solubility, capacity of water retention, capacity of oil retention and emulsifying capacity.
\end{abstract}

Keywords: fish; enzymatic hydrolysate; functional properties.

\section{INTRODUÇÃO}

As proteínas hidrolisadas de pescado são obtidas mediante um processo proteolítico enzimático em que as enzimas vegetais e/ou microbianas atuam como catalisadores biológicos que aceleram a hidrólise das proteínas, promovendo seu isolamento a partir do pescado. As proteínas, como resultado da clivagem de suas ligações peptídicas, são transformadas em peptídeos de diferentes tamanhos e em aminoácidos livres. A matéria-prima geralmente utilizada na obtenção de hidrolisados proteicos é descarte comestível do processamento de pescado magro, visto que espécies com alto teor de gordura promovem o desenvolvimento de aromas intensos no produto elaborado. ${ }^{1}$

Os hidrolisados proteicos podem ser obtidos basicamente por três métodos: a hidrólise alcalina, a hidrólise enzimática e a hidrólise ácida. ${ }^{2}$ A utilização de proteases específicas apresenta algumas vantagens sobre a hidrólise alcalina ou ácida, como a especificidade, o controle do grau de hidrólise, as condições moderadas de ação e o menor conteúdo de sal no hidrolisado final. Além disso, as enzimas podem ser empregadas, geralmente, em concentrações muito baixas, sendo desnecessária sua remoção.

A modificação da estrutura da proteína pela hidrólise enzimática é empregada com o intuito de melhorar as propriedades funcionais, devido a sua especificidade e capacidade de modificar uma grande variedade de grupos funcionais. ${ }^{3,4}$

O grau de hidrólise pode influenciar as características funcionais do produto final, como solubilidade, capacidade de retenção de água, formação de espuma e emulsificação. Um aumento no tempo de hidrólise ou na relação enzima/substrato resulta em uma redução do comprimento médio da cadeia de peptídeos na fração solúvel (proteína hidrolisada). Porém, uma proteólise prolongada poderá resultar na formação de peptídeos extremamente solúveis com propriedades funcionais indesejáveis e promover a formação do gosto amargo. ${ }^{5}$

A enzima Alcalase é uma protease bacteriana alcalina produzida por Bacillus licheniformis e tem sido considerada por muitos pesquisadores uma das melhores enzimas utilizadas na preparação de hidrolisados proteicos. ${ }^{6-8}$ A Flavourzyme também tem sido muito usada na produção de hidrolisados proteicos com excelentes propriedades funcionais. ${ }^{6}$ A protease Novozym, também de origem

*e-mail: dqmprent @furg.br microbiana não apresenta dados na literatura sobre a sua utilização em hidrolisados proteicos de pescado, por isso torna-se interessante o estudo desta enzima e sua comparação com outras enzimas que possuam propriedades já conhecidas.

O objetivo do presente estudo foi avaliar a influência de diferentes enzimas proteolíticas (Alcalase, Flavourzyme e Novozym) sobre as propriedades funcionais de hidrolisados proteicos de Cabrinha (Prionotus punctatus).

\section{PARTE EXPERIMENTAL}

\section{Material}

A matéria-prima utilizada foi a Cabrinha (Prionotus punctatus), pescado magro de baixo valor comercial, fornecida pela Indústria Pescal localizada na cidade de Rio Grande, RS. As enzimas proteolíticas de origem microbiana utilizadas foram Alcalase ${ }^{\circledR}$, Flavourzyme ${ }^{\circledR}$ e Novozym $^{\circledR}$ fornecidas pela Novozymes Latin American Limited (Araucária/Brasil).

\section{Atividade específica}

A atividade específica das enzimas foi determinada pelo método de Rebeca et al. ${ }^{9}$ nas seguintes condições de reação: concentração de caseína $2 \%$ p/v; concentração de enzima 1\% p/p; 120 min de reação; $\mathrm{pH}$ e temperatura ótima de cada enzima. A atividade específica das enzimas foi expressa em U/mg de proteína, sendo que uma unidade de atividade (U) corresponde a $1 \mu \mathrm{mol}$ de tirosina/h.

\section{Grau de hidrólise (GH)}

O grau de hidrólise de cabrinha (Prionotus punctatus) foi determinado pelo método descrito por Pezoa e Salas-Mellado ${ }^{10}$ e expresso segundo a relação da quantidade de proteínas totais presentes no substrato, determinadas pelo método de Kjeldahl ${ }^{11}$ e a quantidade de proteínas solúveis, determinada pelo método de Lowry et al. ${ }^{12}$ A reação enzimática foi realizada em reator de vidro encamisado conectado a um banho ultratermostático com agitação constante através de um agitador de eixo hélice. As condições de hidrólise foram as seguintes: para a Alcalase, a concentração substrato/tampão 
foi de $1 \mathrm{~g} / \mathrm{mL} ; 0,5 \%$ de enzima/substrato; $\mathrm{pH} 8$ e 60 min de reação a $60{ }^{\circ} \mathrm{C}$; para a Flavourzyme a concentração substrato/tampão foi de $1 \mathrm{~g} / \mathrm{mL} ; 2 \%$ de enzima/substrato; pH 7 e 60 min de reação a 50 ${ }^{\circ} \mathrm{C}$; e para Novozym, a concentração substrato/tampão foi de $1 \mathrm{~g} /$ $\mathrm{mL} ; 2 \%$ de enzima/substrato; $\mathrm{pH} 8$ e 60 min de reação a $40{ }^{\circ} \mathrm{C}$. As condições de reação das enzimas Alcalase e Flavourzyme foram seguidas conforme estudo de $\operatorname{Santos}^{13}$ e para a enzima Novozym foi necessária a realização de testes preliminares para determinação das melhores condições. Alíquotas foram retiradas em intervalos de 0, 15, 30, 45 e 60 min, misturadas com ácido tricloroacético (TCA $6,25 \%$ ) e filtradas, no filtrado foi determinada a concentração de proteínas solúveis.

\section{Composição química}

A matéria-prima e os hidrolisados proteicos foram avaliados pela composição centesimal: proteínas (Kjeldahl, N x 6,25), lipídios (Soxhlet), cinza (incineração e mufla, $550-600{ }^{\circ} \mathrm{C}$ ) e umidade (estufa $105^{\circ} \mathrm{C}$ ), conforme método descrito pela AOAC. ${ }^{11}$

\section{Obtenção do hidrolisado proteico de pescado}

A polpa de pescado foi triturada e homogeneizada com solução tampão no pH ótimo de cada enzima (Alcalase, pH 8; Flavourzyme, pH 7 e Novozym, pH 8) e submetida à reação de hidrólise. Ao final dos 60 min de reação o hidrolisado foi submetido ao aquecimento a $95^{\circ} \mathrm{C}$ durante 15 min para interromper a ação da enzima. Após a inativação térmica, o hidrolisado foi centrifugado a uma velocidade de 8667 g por 60 min e separou-se a fração proteica solúvel (camada intermediária) e descartou-se a fase lipídica (camada superior) e as proteínas insolúveis (camada inferior).

\section{Propriedades funcionais dos hidrolisados enzimáticos}

\section{Solubilidade proteica}

A solubilidade proteica foi determinada através do método de Morr et al. ${ }^{14}$ com variação de $\mathrm{pH}$ na faixa de 3 a 11 . Uma amostra

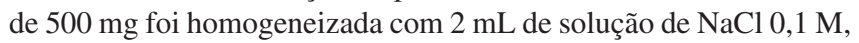
obtendo-se uma pasta homogênea. A seguir adicionou-se $40 \mathrm{~mL}$ de tampão fosfato em pH 3, 5, 7, 9 e 11, a suspensão foi mantida sob agitação por 45 min em agitador magnético e o volume foi completado em balão volumétrico de $50 \mathrm{~mL}$. Após, a suspensão foi centrifugada a $960 \mathrm{~g}$ por 30 min e no sobrenadante foi determinada a concentração de proteínas solúveis pelo método de Lorry et al.. ${ }^{12}$ A porcentagem de proteína solúvel foi calculada de acordo com a Equação 1.

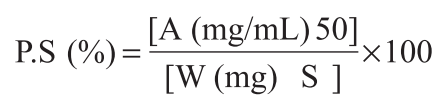

$$
\begin{aligned}
& \overline{100}
\end{aligned}
$$

onde: P.S = teor de proteínas solúveis presentes na amostra [\%]; A = concentração proteica do sobrenadante $[\mathrm{mg} / \mathrm{mL}] ; \mathrm{W}=$ peso da amostra [mg]; S = concentração de proteína na amostra [\%].

\section{Capacidade de retenção de água}

A capacidade de retenção de água (CRA) foi determinada de acordo com o método de Regenstein et al. ${ }^{15}$ com algumas modificações. Dispersões proteicas a $1 \%$ foram homogeneizadas com $2 \mathrm{~mL}$ de solução de $\mathrm{NaCl}$ 0,1 M e $38 \mathrm{~mL}$ de tampão fosfato em $\mathrm{pH}$ 3, 5, 7,9 e 11. A dispersão proteica foi submetida à agitação por 15 min e centrifugada a $960 \mathrm{~g}$ por $25 \mathrm{~min}$. As proteínas que se solubilizaram foram quantificadas no sobrenadante pelo método de Lowry et al. ${ }^{12}$ e diminuídas das proteínas totais presentes na amostra. A CRA foi expressa em volume de água retida pela quantidade de proteína total presente na amostra (mL de água/g de proteína).

\section{Capacidade de retenção de óleo}

A capacidade de retenção de óleo (CRO) foi determinada de acordo com o método de Fonkwe e Singh. ${ }^{16}$ Um grama de proteína foi homogeneizado com $20 \mathrm{~mL}$ de óleo vegetal e submetido a agitação por 10 min em agitador magnético, a suspensão foi centrifugada a 8667 g por 15 min. O resultado foi expresso em volume de óleo retido pela quantidade de proteína total presente na amostra.

\section{Propriedades espumantes}

A capacidade de formação de espuma (CFE) e a estabilidade de espuma (EEs) foram avaliadas por uma combinação dos métodos de Phillips et al. ${ }^{17}$ e Dipak e Kumar. ${ }^{18}$ Três gramas de amostra foram misturados com $100 \mathrm{~mL}$ de água destilada, deixando-se em repouso por 10 min. A suspensão proteica foi submetida à agitação em um blender por $1 \mathrm{~min}$, em seguida a mesma foi transferida para uma proveta de $250 \mathrm{~mL}$, medindo-se o volume antes e após o batimento. $\mathrm{O}$ estudo da estabilidade da espuma foi feito através do repouso da amostra à temperatura ambiente $\left(22-25^{\circ} \mathrm{C}\right)$ com leitura do volume total após intervalos de 5, 10, 15, 30 e $60 \mathrm{~min}$.

\section{Propriedades emulsificantes}

A capacidade emulsificante (CE) e a estabilidade de emulsão (EEm) foram determinadas segundo o método de Okezie e Bello, ${ }^{19}$ com algumas modificações. Um grama de proteína foi homogeneizada com $34 \mathrm{~mL}$ de solução de $\mathrm{NaCl} 3 \%$ e foi submetida à agitação em agitador (modelo SB40 - Black e Decker) por $30 \mathrm{~s}$ e iniciou-se a adição de óleo vegetal através de uma bureta até formar a emulsão. O resultado foi expresso em volume de óleo gasto para formar a emulsão pela quantidade de proteína total presente na amostra. Para determinação da estabilidade foi necessário aquecer a emulsão em banho-maria a $80{ }^{\circ} \mathrm{C}$ por $30 \mathrm{~min}$, resfriar em água corrente por 15 min e centrifugar a 240 g por 15 min. A estabilidade de emulsão foi expressa em porcentagem da relação entre o volume da camada emulsificada remanescente e o volume total da camada emulsificada.

\section{Análise estatística}

Os resultados foram avaliados estatisticamente mediante a Análise de Variância (ANOVA) e as médias comparadas entre si através do teste de Tukey ao nível de 5\% de significância. As análises foram realizadas em triplicata.

\section{RESULTADOS E DISCUSSÃO}

\section{Atividade específica das enzimas}

A caseína é a proteína mais utilizada como substrato para medida de atividade específica de enzimas proteolíticas em condições neutras ou alcalinas. A atividade específica para caseína das enzimas Alcalase, Flavourzyme e Novozym foi de 36,0; 22,2 e 70,8 U/mg de proteína, respectivamente, apresentando diferença significativa $(\mathrm{p}<0,05)$. Entende-se que uma unidade de atividade $(\mathrm{U})$ corresponde a $1 \mu \mathrm{mol}$ de tirosina/h.

Os resultados mostraram que houve diferença significativa $(\mathrm{p} \leq 0,05)$ entre a atividade específica das enzimas estudadas, sendo que a enzima Novozym apresentou a maior atividade comparada com as enzimas Alcalase e Flavourzyme. Gildberg et al. ${ }^{20}$ encontraram um resultado maior de atividade específica para a enzima Alcalase que foi em torno de $60 \mathrm{U} / \mathrm{mg}$. 
Esta diferença entre os resultados encontrados de atividade específica da enzima Alcalase pode ser atribuída às diferenças de condições de tempo e temperatura de armazenamento, pois a atividade da enzima costuma ser reduzida com o aumento no tempo de armazenamento.

\section{Grau de hidrólise}

O grau de hidrólise é um parâmetro utilizado para comparar hidrolisados proteicos entre si. ${ }^{21}$ Os resultados do grau de hidrólise da polpa de Cabrinha (Prionotus punctatus) com as diferentes enzimas proteolíticas estão apresentados na Tabela 1.

Tabela 1. Grau de hidrólise (GH) de polpa de Cabrinha utilizando as enzimas Alcalase, Flavourzyme e Novozym

\begin{tabular}{lccc}
\hline $\begin{array}{l}\text { Tempo de } \\
\text { hidrólise } \\
(\mathrm{min})\end{array}$ & GH $(\%)^{*}$ & $\mathrm{GH}(\%)^{*}$ & $\mathrm{GH}(\%)^{*}$ \\
\hline 15 & Alcalase & Flavourzyme & Novozym \\
30 & $22,66 \mathrm{bAB}$ & $22,08 \mathrm{aB}$ & $23,73 \mathrm{bA}$ \\
45 & $23,03 \mathrm{bB}$ & $23,28 \mathrm{aAB}$ & $24,30 \mathrm{bA}$ \\
60 & $25,41 \mathrm{aAB}$ & $23,68 \mathrm{aB}$ & $27,96 \mathrm{aA}$ \\
\hline
\end{tabular}

*Médias seguidas por letras minúsculas diferentes, na mesma coluna, e por letras maiúsculas diferentes, na mesma linha, diferem estatisticamente pelo teste de Tukey $(\mathrm{p}<0,05)$.

O grau de hidrólise das enzimas aumentou com o aumento do tempo de reação de hidrólise, sendo que a maior quantidade de proteína hidrolisada foi nos primeiros $30 \mathrm{~min}$ de reação. Para a enzima Alcalase e Novozym houve um aumento no grau de hidrólise após 45 min de reação, no entanto para a enzima Flavourzyme o grau de hidrólise não foi alterado depois dos 30 min de hidrólise. Aos 60 min de reação a enzima Alcalase apresentou um grau de hidrólise intermediário em relação à Flavourzyme e à Novozym não diferindo significativamente $(\mathrm{p} \leq 0,05)$. No entanto o grau de hidrólise da Novozym foi significativamente maior que o grau de hidrólise da Flavourzyme, como se pode observar na Tabela 1.

Foi observada uma relação entre a atividade específica das enzimas e o grau de hidrólise, ou seja, quanto maior a atividade da enzima maior a quebra das proteínas em peptídios menores. É importante um rígido controle da hidrólise, pois são desejáveis baixas porcentagens de grau de hidrólise para prevenir o desenvolvimento de amargor e a conservação das propriedades funcionais dos hidrolisados. ${ }^{6}$

Segundo Santos, ${ }^{13}$ que estudou o grau de hidrólise obtido com a enzima Flavourzyme, na elaboração de hidrolisado de Cabrinha (Prionotus punctatus) nas mesmas condições de tempo e temperatura de reação, o grau de hidrólise encontrado foi de 24,7\%. Diniz e Martin ${ }^{22}$ que estudaram o efeito do $\mathrm{pH}$, temperatura e proporção de enzima-substrato no grau de hidrólise de proteína de músculo de cação com a enzima Alcalase encontraram 15,6\% de grau de hidrólise com uma concentração de enzima-substrato $2 \%$.

\section{Composição química}

A Tabela 2 apresenta a composição proximal dos hidrolisados de Cabrinha (Prionotus punctatus) com as diferentes enzimas, expressa em base seca.

A elevada concentração de cinza verificada nos hidrolisados proteicos, de 4,63 a $8,12 \%$, é decorrente de sais presentes nos tampões utilizados para manter o $\mathrm{pH}$ durante a hidrólise enzimática. Os teores de cinza dos hidrolisados elaborados com as enzimas Alcalase, Flavourzyme e Novozym apresentaram diferença significativa $(p<0,05)$ entre si. As enzimas Alcalase e Novozym agem em pH 8, ou seja, apresentam suas condições ótimas em pH alcalino, por isso necessitam uma concentração maior de fosfato comparado com a enzima Flavourzyme que agem em $\mathrm{pH}$ neutro ( $\mathrm{pH}$ 7). Sendo assim, o hidrolisado obtido com a enzima Flavourzyme apresentou menor teor de cinza, diferindo significativamente dos hidrolisados com Alcalase e Novozym. Elevados teores de cinza (14\%) também foram encontrados por Diniz e Martin ${ }^{22}$ em estudo realizado com cação. O baixo teor de lipídios encontrado nos hidrolisados constitui um aspecto favorável em relação à oxidação lipídica e à estabilidade durante o armazenamento. ${ }^{7}$ Os hidrolisados apresentaram elevados teores de proteína em base seca, de 87,84 a 92,39\%, sendo que o hidrolisado obtido com a enzima Alcalase apresentou menor conteúdo proteico comparado com os hidrolisados com a Flavourzyme e Novozym diferindo significativamente $(\mathrm{p}<0,05)$. O conteúdo de proteína dos hidrolisados apresentou-se dentro da faixa encontrada em outros trabalhos que apresentaram uma variação entre 62 a $90 \%$ de proteína. ${ }^{6,23}$

Tabela 2. Composição química dos hidrolisados proteicos obtidos com as enzimas Alcalase, Flavourzyme e Novozym.

\begin{tabular}{lccc}
\hline Produto & $\begin{array}{c}* \text { Cinza } \\
(\%) \mathrm{b} . \mathrm{s}\end{array}$ & $\begin{array}{c}* \text { Lipídios } \\
(\%) \mathrm{b} . \mathrm{s}\end{array}$ & $\begin{array}{c}* \text { Proteínas } \\
(\%) \mathrm{b} . \mathrm{s}\end{array}$ \\
\hline $\begin{array}{l}\text { Hidrolisado - } \\
\text { Alcalase }\end{array}$ & $8,12 \mathrm{a}$ & $4,04 \mathrm{a}$ & $87,84 \mathrm{~b}$ \\
$\begin{array}{l}\text { Hidrolisado - } \\
\text { Flavourzyme }\end{array}$ & $4,63 \mathrm{c}$ & $2,97 \mathrm{a}$ & $92,39 \mathrm{a}$ \\
$\begin{array}{l}\text { Hidrolisado - } \\
\text { Novozym }\end{array}$ & $6,72 \mathrm{~b}$ & $2,75 \mathrm{a}$ & $90,53 \mathrm{a}$ \\
\hline
\end{tabular}

*Médias seguidas por letras diferentes, na mesma coluna, diferem estatisticamente pelo teste de Tukey $(\mathrm{p}<0,05)$.

\section{Propriedades funcionais dos hidrolisados proteicos}

\section{Solubilidade}

A Figura 1 mostra a curva de solubilidade proteica dos hidrolisados proteicos obtidos com as enzimas Alcalase, Flavourzyme e Novozym nos pHs 3, 5, 7, 9 e 11 .

$\mathrm{O}$ pH de mínima solubilidade para todos os hidrolisados ficou na região de 5,0, aumentando à medida que o $\mathrm{pH}$ atinge a faixa alcalina, como ocorre com a maioria das proteínas, pois em $\mathrm{pH}$ ácido ou alcalino, há um aumento nas interações entre as moléculas de proteína e água, aumentando a solubilidade proteica. ${ }^{24}$

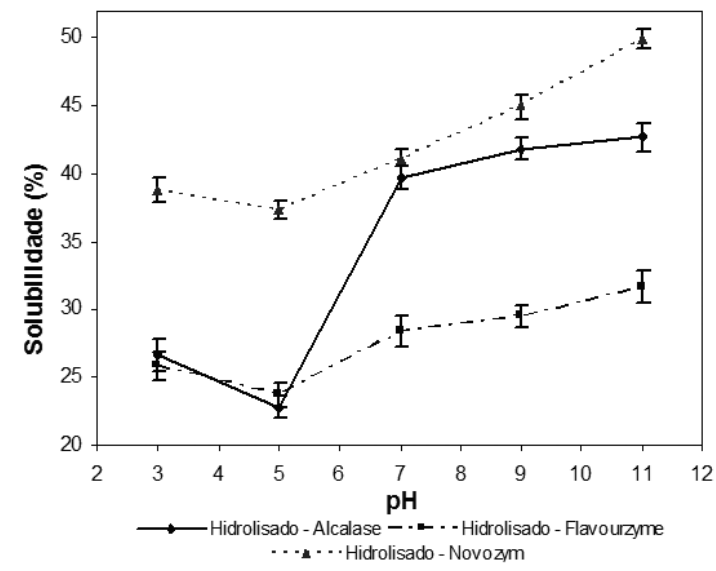

Figura 1. Curva de solubilidade dos hidrolisados protéicos obtidos com as enzimas Alcalase, Flavourzyme e Novozym (os resultados são médias de três determinações e as barras verticais expressam o desvio padrão da média) 
Com base na Figura 1, pode-se notar que o hidrolisado obtido com a enzima Novozym apresentou maior solubilidade proteica em comparação aos demais hidrolisados. Observa-se uma correlação entre o grau de hidrólise e a solubilidade do hidrolisado, pois quanto maior a quebra das proteínas, maior a solubilização destas. ${ }^{25}$

Os resultados de solubilidade dos hidrolisados enzimáticos estão coerentes com a literatura, pois Santos ${ }^{13}$ encontrou uma faixa de 39 a $42 \%$ de solubilidade em pHs entre 3 e 11 para o hidrolisado de Cabrinha (Prionotus punctatus) obtido com a enzima Alcalase e 34 a $38 \%$ para o hidrolisado obtido com a enzima Flavourzyme na mesma faixa de $\mathrm{pH}$.

Embora o aumento da solubilidade tenha uma relação positiva com a extensão da hidrólise, deve-se ter cuidado para que o substrato não seja extensivamente hidrolisado, pois um alto grau de hidrólise pode ter efeitos negativos nas demais propriedades funcionais do hidrolisado.

\section{Capacidade de retenção de água}

A Figura 2 apresenta a curva de capacidade de retenção de água dos hidrolisados em diferentes pHs.

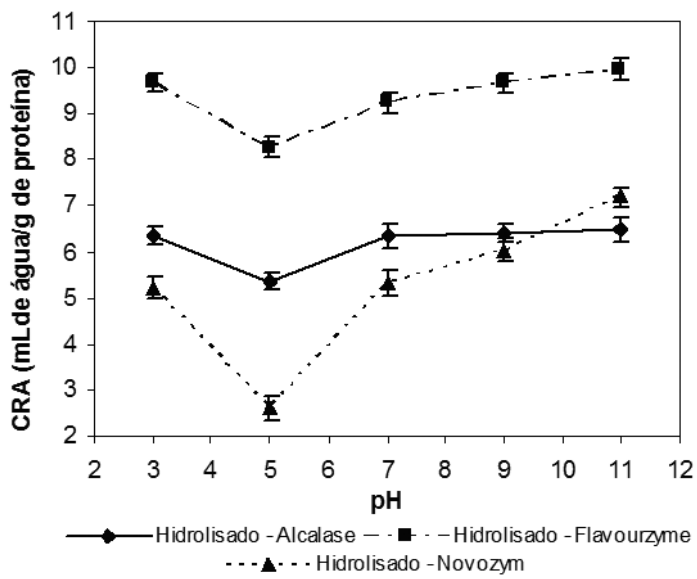

Figura 2. Capacidade de retenção de água (CRA) dos hidrolisados protéicos obtidos com as enzimas Alcalase, Flavourzyme e Novozym (os resultados são médias de três determinações e as barras verticais expressam o desvio padrão da média)

A capacidade de retenção de água é um fenômeno importante na tecnologia de alimentos, pois a água absorvida em pequenas quantidades não atua como solvente, mas contribui para dar corpo e aumentar a viscosidade. ${ }^{24}$ De acordo com Cheftel et al. ${ }^{26}$ não existe relação entre solubilidade e capacidade de absorção de água. Com base na Figura 2, verificou-se que o hidrolisado obtido com a enzima Flavourzyme apresentou a maior CRA, o aumento da retenção de água foi inversamente proporcional ao grau de hidrólise do substrato. $\mathrm{O}$ comportamento da capacidade de retenção de água dos hidrolisado em $\mathrm{pH} 5$ pode ser consequência da redução da capacidade da proteína se ligar à água, devido às interações intermoleculares.

Os resultados encontrados para capacidade de retenção de água dos hidrolisados (Figura 2) foram superiores ao encontrado por Cândido e Sgarbieri ${ }^{25}$ em estudo com hidrolisado de pescado, que apresentou valores de CRA entre 3,0 e 3,5 mL de água/g de proteína e os autores concluiram que hidrolisados com maior grau de hidrólise absorveram mais água que hidrolisados com menor grau de hidrólise.

\section{Capacidade de retenção de óleo}

A capacidade de retenção de óleo de um hidrolisado é um atributo que não só influencia no sabor do produto, mas também é uma importante característica funcional, requerida principalmente para a indústria de carnes emulsionadas. A Figura 3 apresenta a capacidade de retenção de óleo dos hidrolisados.

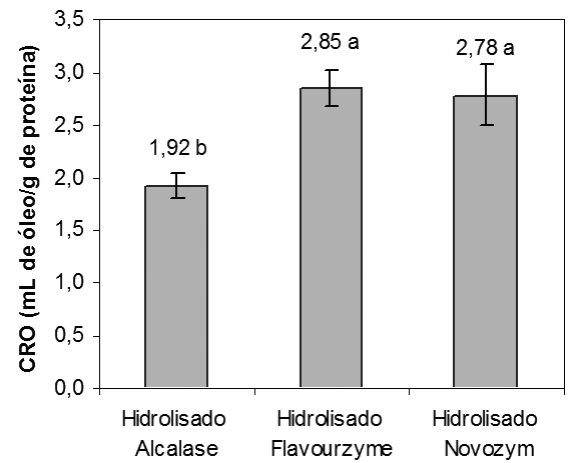

Figura 3. Capacidade de retenção de óleo (CRO) dos hidrolisados protéicos obtidos com as enzimas Alcalase, Flavourzyme e Novozym [médias seguidas de letras diferentes, diferem estatisticamente pelo teste de Tukey $(p<0,05)]$

A absorção de óleo varia em função do número de grupos hidrofóbicos expostos da proteína. As cadeias laterais não polares das proteínas têm afinidade com as cadeias hidrofóbicas da molécula de gordura e assim contribuem para a absorção de gordura. ${ }^{27}$

Pode-se verificar (Figura 3) que houve diferença significativa $(p<0,05)$ entre a capacidade de retenção de óleo do hidrolisado obtido com a enzima Alcalase, quando comparada com os hidrolisados obtidos com as enzimas Flavourzyme e Novozym. Estes resultados são semelhantes ao encontrado por Wasswa et al.,${ }^{28}$ que estudaram o efeito do grau de hidrólise nas propriedades funcionais de hidrolisado proteico de pescado obtido com a enzima Alcalase, e observaram uma capacidade de retenção de óleo de $2,4 \mathrm{~mL}$ de óleo/g de proteína para um hidrolisado com 14,9\% de grau de hidrólise.

\section{Propriedades espumantes}

A análise comparativa da capacidade de formação de espuma e estabilidade de espuma dos hidrolisados de pescado obtidos com as enzimas proteolíticas, destacada pela estabilidade de espuma após o período de 15 min, está apresentada na Figura 4.

Com base na Figura 4, pode-se observar que a capacidade de formação de espuma do hidrolisado obtido com a enzima Alcalase foi maior, diferindo estatisticamente $(\mathrm{p}<0,05)$ dos hidrolisados obtidos com as enzimas Flavourzyme e Novozym; isto pode ser explicado pelo grau de hidrólise intermediário das proteínas do hidrolisado obtido com a enzima Alcalase, favorecendo a capacidade de formação de espuma. ${ }^{29}$ A funcionalidade das proteínas do hidrolisado pode ser influenciada

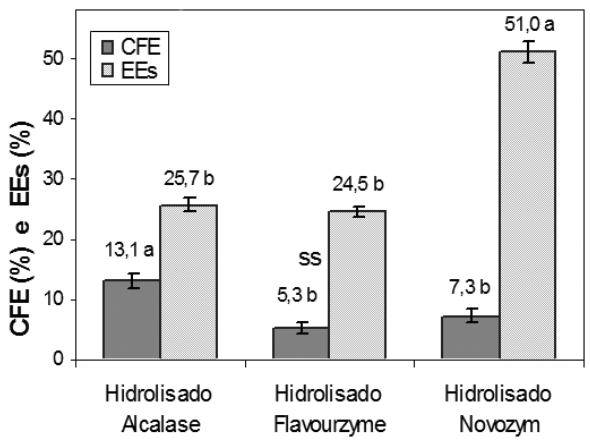

Figura 4. Capacidade de formação de espuma (CFE) e estabilidade de espuma (EEs) após 15 min dos hidrolisados protéicos obtidos com as enzimas Alcalase, Flavourzyme e Novozym [médias para a mesma propriedade seguidas de letras diferentes, diferem estatisticamente pelo teste de Tukey $(p<0,05)]$ 
devido à composição e o grau de desnaturação dessas proteínas, além da especificidade da enzima utilizada. Shahidi et al. ${ }^{8}$ obtiveram $90 \%$ de capacidade de formação de espuma para hidrolisado proteico de Capelim (Mallotus villosus) elaborado com a enzima Alcalase.

A estabilidade de espuma dos hidrolisados foi relativamente baixa, pois apresentou uma faixa de 20 a $50 \%$ após $15 \mathrm{~min}$, chegando a $0 \%$ após $60 \mathrm{~min}$ de repouso. Apesar do hidrolisado obtido com a enzima Novozym ter apresentado baixa CFE, este apresentou a maior Ees, diferindo significativamente $(\mathrm{p}<0,05)$ dos demais hidrolisados. A estabilidade de espuma de hidrolisado proteico de pescado também foi estudada por Shahidi et al., ${ }^{8}$ que encontraram $170 \%$ de estabilidade em 0,5 min e $0 \%$ de estabilidade após $60 \mathrm{~min}$.

\section{Propriedades emulsificantes}

A Figura 5 apresenta a capacidade emulsificante e a estabilidade de emulsão dos hidrolisados de pescado obtidos com as enzimas Alcalase, Flavourzyme e Novozym.

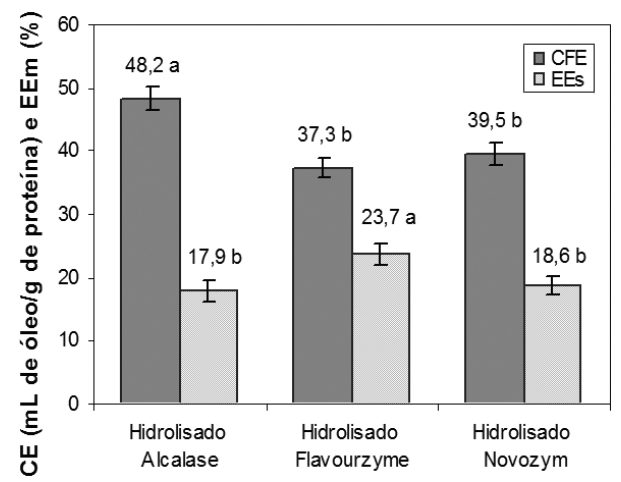

Figura 5. Capacidade emulsificante (CE) e estabilidade de emulsão (EEm) dos hidrolisados enzimáticos [médias para a mesma propriedade seguidas de letras diferentes, diferem estatisticamente pelo teste de Tukey $(p<0,05)]$

Através da Figura 5, pode-se observar que a capacidade emulsificante do hidrolisado obtido com a enzima Alcalase foi maior, diferindo significativamente $(\mathrm{p}<0,05)$ dos hidrolisados obtidos com as enzimas Flavourzyme e Novozym. Os resultados de capacidade de emulsão dos hidrolisados foram semelhantes ao encontrado na literatura, no entanto a estabilidade de emulsão foi baixa. Shahidi et al., ${ }^{8}$ que estudaram propriedades emulsificantes de hidrolisados proteicos de pescado, obtiveram 50,9 e 92,0\% de capacidade emulsificante e estabilidade de emulsão, respectivamente.

A hidrólise enzimática influencia negativamente na capacidade de formar emulsão à medida que o grau de hidrólise aumenta. ${ }^{6,30}$ Portanto, $\mathrm{o}$ melhor comportamento da capacidade de emulsão do hidrolisado obtido com a enzima Alcalase pode ser explicado pelo grau de hidrólise intermediário apresentado em relação à enzima Flavourzyme e Novozym.

A estabilidade de emulsão do hidrolisado obtido com a enzima Flavourzyme apresentou-se significativamente maior $(\mathrm{p}<0,05) \mathrm{em}$ relação aos hidrolisados com as enzimas Alcalase e Novozym. Kristinsson e Rasco ${ }^{6}$ obtiveram em torno de $50 \%$ de estabilidade de emulsão para hidrolisados proteicos de pescado com as enzimas Alcalase e Flavourzyme e esta estabilidade foi maior para o hidrolisado com menor grau de hidrólise.

\section{CONCLUSÃO}

Os hidrolisados de Cabrinha apresentaram alto conteúdo proteico e excelentes propriedades funcionais, principalmente solubilidade, capacidade de retenção de água e óleo e capacidade emulsificante. A enzima Novozym apresentou o melhor comportamento frente ao grau de hidrólise e à funcionalidade do hidrolisado proteico obtido, mostrando propriedades semelhantes às enzimas usualmente utilizadas na obtenção de hidrolisados proteicos de pescado.

\section{AGRADECIMENTOS}

Ao $\mathrm{CNPq}$ pelo financiamento do projeto e à FAPERGS pelas bolsas concedidas.

\section{REFERÊNCIAS}

1. Furlan, E. F.; Oetterer, M.; Rev. Ciênc. Tecnol. 2002, 10, 79.

2. Lahl, W. J.; Braun, S. D.; Food Technol. 1994, 48, 68.

3. Bhaskar, N.; Modi, V. K.; Govindaraju, K.; Radha, C.; Lalitha, R. G.; Bioresour. Technol. 2007, 98, 388.

4. Silva, V. D. M.; Silvestre, M. P. C.; Food Sci. Technol. 2003, 37, 709.

5. Diniz, F. M.; Martin, A M. Em Manual de Pesca; Ogawa, M.; Maia, E. L., eds.; Varela: São Paulo, 1999.

6. Kristinsson, H. G.; Rasco, B. A.; Crit. Rev. Food Sci. Nutrition. 2000, $40,43$.

7. Hoyle, N. T.; Merritt, J. H.; J. Food Sci. 1994, 59, 76.

8. Shahidi, F.; Han, X. Q.; Synowiecki, J.; Food Chem. 1995, 53, 285.

9. Rebeca, B. D.; Peña-Vera, M. T.; Díaz-Castañeda, M.; J. Food Sci. 1991, $56,309$.

10. Pezoa, V.; Salas-Mellado, M. M.; Obtenção de um concentrado de proteínas de pescado para alimentos, pelo método enzimático, utilizando as próprias enzimas do pescado, $1^{\text {a }}$ ed., Editora FURG: Rio Grande, 1979.

11. AOAC; Official Methods of Analysis, $16^{\text {th }}$ ed., Arlington, 1997.

12. Lowry, O. H.; Rosenbrough, N. J.; Farr, A. L.; Randall, R. J.; J. Biol. Chem. 1951, 193, 265.

13. Santos, S. D.; Dissertação de Mestrado, Universidade Federal do Rio Grande, Brasil, 2006.

14. Morr, C. V.; German, B.; Kinsella, J. E.; Regenstein, J. M.; Van Buren, J. P.; Kilara, A.; Lewis, B. A.; Mangino, M. E.; J. Food Sci. 1985, 50, 1715.

15. Regenstein, J. M.; Jauregui, C. A.; Baker, R.; J. Food Biochem. 1984, 8, 123.

16. Fonkwe, L. G.; Singh, R. K.; Process Biochem. 1996, 31, 605.

17. Phillips, L. G.; Haque, Z.; Kinsella, J. E.; J. Food Sci. 1987, 52, 1074.

18. Dipak, K. D.; Kumar, D. M.; J. Agric. Food Chem. 1986, 34, 775.

19. Okezie, B. O.; Bello, A. B.; J. Food Sci. 1988, 53, 450.

20. Gildberg, A.; Arnesen, J. A.; Carlehog, M.; Process Biochem. 2002, 38, 475.

21. Neves, R. A. M.; De Mira, N. V. M.; Lanfer Marquez, U. M.; Ciênc. Tecnol. Alim. 2004, 24, 101

22. Diniz, F. M.; Martin, A. M.; Int. J. Food Sci. Technol. 1996, 31, 419

23. Nilsang, S.; Lertsiri, S.; Suphantharika, M.; Assavanig, A.; J. Food Engineering 2005, 70, 571 .

24. Cândido, L. M. B.; Nogueira, A. K; Sgarbieri, V. C.; Braz. J. Food Technol. 1998, 1,77 .

25. Cândido, L. M. B.; Sgarbieri, V. C.; J. Sci. Food Agric. 2003, 83, 937.

26. Cheftel, J. C.; Cuq, J. L.; Lorient, D.; Proteínas Alimentarias, Editorial Acribia, S.A.: Zaragoza, 1989.

27. Donadel, M. E.; Prudêncio-Ferreira, S. H.; Ciênc. Tecnol. Alim. 1999, 19,380 .

28. Wasswa, J.; Tang, J.; Gu, X. H.; Yuan, X. Q.; Food Chem. 2007, 104, 1698.

29. Sgarbieri, V. C.; Bol. Soc. Bras. Ciênc. Tecnol. Alim. 1998, 32, 105.

30. Quaglia, G. B.; Orban, E.; J. Food Sci. 1990, 55, 1571. 